\title{
LANDSLIDE SUSCEPTIBILITY ASSESSMENT USING GIS-BASED MODEL AND REMOTE SENSING DATA
}

\author{
Narges Fatholahi $^{{ }^{*}}$, Farimah Bakhshizadeh ${ }^{2}$ \\ MSc. of Geomatics Engineering, Geomatics and Geospatial Information Department, \\ Faculty of Engineering, University of Tehran, Tehran, Iran; \\ MSc. of Geography, Remote Sensing and Geographic Information System \\ Department, University of Kharazmi, Teharan, Iran;
}

Corresponding Author Narges Fatholahi, e-mail: nfatholahi7@gmail.com;

Received October 2019; November 2019; Published December 2019;

DOI: https://doi.org/10.31407/ijees9428

\begin{abstract}
Landslide is one of the disasters, which occurs throughout the world under all climatic conditions and terrain. This leads to the loss of lives and property and damage to the natural environment. Therefore, a need arises for the landslide hazard zonation for the identification of potential landslide areas. This research is an attempt towards modeling the landslide using GIS and remote sensing techniques. Phuentsholing-Pasakha highway has been selected for the study due to its importance in the economy of the country. Parameters causing landslides were determined through a thorough literature review and field investigations. These parameters were then converted in the form of maps using ArcGIS 10 software. The weights for each parameter were assigned using a bivariate statistical analysis method for spatial analysis in GIS. Landslide hazard map has been obtained, which demarcates the study area into three levels of hazard viz. high, medium, and low danger. About $19.35 \%$ of the area falls under high hazard, $30.55 \%$ falls under medium hazard, and $50.10 \%$ area falls under low risk.
\end{abstract}

Keywords: Landslides, remote sensing, GIS. 